\title{
LITERATURE REVIEW OF ELECTROMAGNETIC ACTUATOR FORCE GENERATION FOR DYNAMIC MODAL TESTING APPLICATIONS
}

\author{
Norlida Jamil $^{1}$, Ahmad Razlan Yusoff ${ }^{2}$ and Mohamad Hatifi Mansor ${ }^{1}$ \\ ${ }^{1}$ Faculty of Mechanical Engineering \\ Universiti Malaysia Pahang, 26600 Pekan, Pahang, Malaysia \\ Email: norlidajamil@gmail.com \\ ${ }^{2}$ Faculty of Manufacturing Engineering \\ Universiti Malaysia Pahang, 26600 Pekan, Pahang, Malaysia
}

\begin{abstract}
Milling is one of the most common manufacturing processes for automotive components, but its productivity is limited by the onset of regenerative chatter. This is a form of unstable self-excited vibration that occurs when the volume of material removed is too large for a particular spindle speed. This form of chatter is undesirable because it results in premature tool wear, poor surface finish on the machined component and the possibility of serious damage to the machine itself. The chatter stability of a milling process can be determined using well-established theory, provided that the frequency response of the flexible structure can be determined. In practice this usually involves the excitation of a stationery (non-rotating) milling tool with a modal hammer, and measurement of the response of the tool with a co-located accelerometer. However, this measurement is not necessarily accurate due to amplitude dependency factor consideration. There is anecdotal evidence that structural nonlinearity can have a significant effect on the chatter stability of some milling machines. This project develops non-contact electromagnetic actuators to measure the frequency response of milling tools to machine automotive parts. In addition it will describe the practical application of this approach, and discuss its amplitude dependency for current excitation during frequency response function measurement using magnetic force generation.
\end{abstract}

Keywords: Chatter, frequency response function, modal testing

\section{INTRODUCTION}

Higher spindle speeds and higher feed rates are needed to increase productivity. For example, an aluminum machined part that can be produced without assembly will reduce time, waste and parts. However, high speed machining problems notably tool chatter in function of both spindle speed and depth of cut. All of these historical and modern chatter prediction models require the frequency response function (FRF) of the cutting tool to determine its dynamic characteristics. Traditionally, an impact hammer is used to excite the system at the tool tip and the response is measured with a co-located accelerometer. However this configuration has a number of disadvantages, such as:

- The cutting edge of the tool can easily be damaged by the hammer strike.

- On large machines the test engineer must work inside the machine itself, which can pose a health and safety hazard. 
- The tool cannot rotate during the test. The FRF during rotation could differ due to gyroscopic forces and bearing loads (de Lacalle \& Lamikiz, 2009). Furthermore some CNC machines automatically modify the tool drawbar force as a function of spindle speed, which may influence the tool's FRF.

- In practice the mechanical interfaces in the system lead to some nonlinearity in the FRF. During machining the tool load differs substantially from the forces induced by an impact hammer, so these nonlinearities cannot be considered.

A non-contact actuator offers advantages, including relative ease of use, reduced test time, a quick and easy setup and removal, and lower cost. The force exerted on the tool and magnetic flux density in the air gap must be maximized, and the overall actuator size minimized. The eddy current losses are proportional to the excitation frequency. The excitation waveform requires that the actuator mount and displacement sensor mount have higher natural frequencies than the tool specimen. To date, non-contact excitation systems have been developed by several researchers. Tatar, Rantatalo, and Gren (2007) and Rantatalo, Aidanpaa, Goransson, and Norman (2007) used laser Doppler vibrometry (LDV) and active magnetic bearing and capacitive sensors to measure the dynamic vibrations of cutting with an optically smooth surface at different cutting speeds. The mass loading, added stiffness and multiple strikes with the traditional impact hammer can be eliminated by introducing a non-contact eddy current excitation method to preserve the structure and mode shape from magnetic actuation. Kiefer (2004) integrated an electromagnet with a receptance coupling substructure to predict chatter. The electromagnet easily and accurately demonstrated the dynamic characteristics of the cutting tool or FRF, and generated a high force amplitude, high bandwidth and controllability force. Caulfield (2002) designed and demonstrated an electromechanical actuator (EMA) that could identify the dynamic characteristics of a machine. The design was based on magnetic circuit analysis, generalized machine theory and the finite element method to confirm the performance. Yusoff and Sims (2008) considered the amplitude dependency of a tool FRF under static conditions. However, previous work has generally not considered the amplitude dependency of the tool FRF under dynamic conditions. Using a non-contacting electromagnet allows such amplitude and speed dependencies to be investigated experimentally. Furthermore, the dynamic properties behaviors to the rotor systems such as the cutting tool should be considered when predicting the stability lobe diagram. This will be the focus of the present project.

\section{IDENTIFYING AND CONTROLLING CHATTER}

Some of benefits of HSM are the reduced processing time, waste and components, thus increasing the quality and quantity. However, machine tool chatter - the self-excited vibration of the milling machine tool - leads to a rough surface finish and machine breakdown, and was a limiting factor. Previous researchers have conducted a lot of research to overcome or avoid chatter. Stability lobe, a spindle speed vs. cutting depth plot, is used to look for the stability boundary to increase the possibility of obtaining high removal rates without chatter (Arnold, 1946; Koenigsberger \& Tlusty, 1967; Merrit, 1965; Tlusty \& Polocek, 1963; Tobias, 1965; Tobias \& Fishwick, 1958; Quintana, Ciurana, \& Teixidor, 2008). To do so, the dynamic behavior of the cutting tool FRF, such as the control parameters, chip width, and spindle speed, were focused on in order to plot these diagrams. The machining parameters were developed before 
came out with derivation of selected algorithm. These studies led to the basic knowledge of the regeneration of waviness, which initiates chatter (Schmitz, Ziegert, \& Stanislaus, 2004). The paper presents a comparison between cutting test results with predicted stability lobes for rotating and non-rotating tools. It shows that the dynamic stiffness increases with an increment in spindle speed. Also, the stable cutting depths increase at higher speeds.

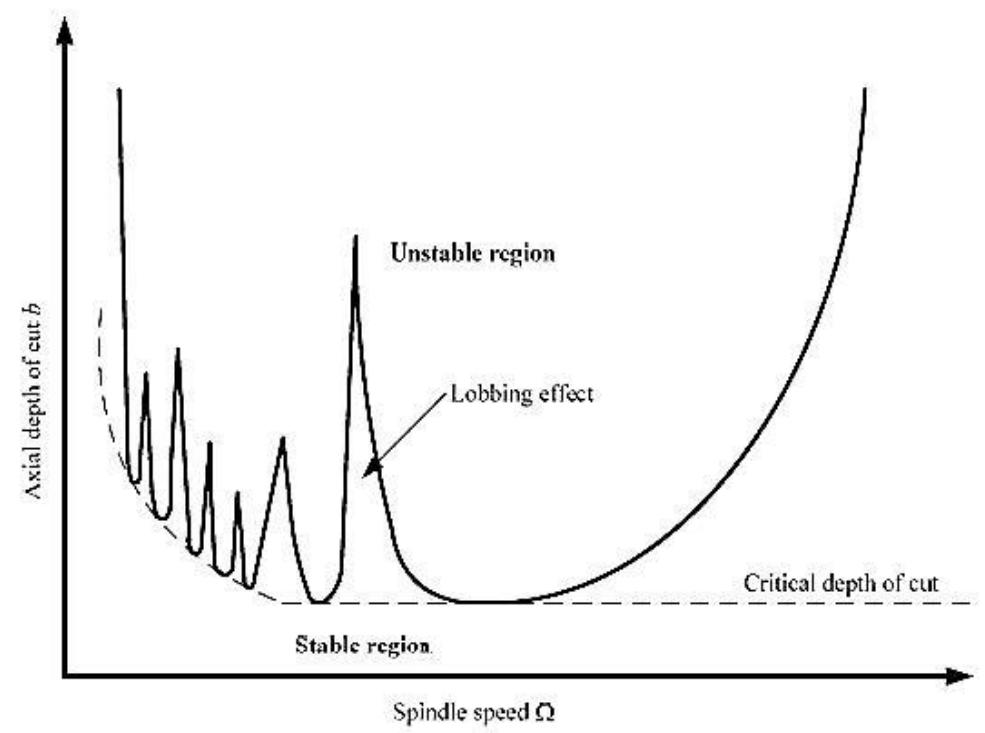

Figure 1. Example of a stability lobe diagram (Yusoff \& Sims, 2011)

Regeneration is major factor in self-excitation behavior that leads to chatter. In addition, the dynamics of the machine tool and cutting force variations are also associated with the occurrence of chatter (Tlusty \& Polocek, 1963; Tobias, 1965; Tobias $\&$ Fishwick, 1958). This theory had been used widely in research aimed at the control and avoidance of chatter. Previous researchers conducted many studies using analytical, computational and experimental analysis. One of analytical method introduced was the Zeroth Order Approximation (ZOD) method, which can obtain accurate Stability Lobe Diagram (SLD) predictions in situations where the cutting force varies relatively little (Altintaş \& Budak, 1995). Another method is modify independent Delay Differential Equation (DDE) into ordinary equation with recognize solution, known as the Semidiscretization (SD) method (Insperger \& Stepan, 2002). Later, an analysis has been conducted between these two methods; both methods were found to produce similar results for high radial immersions, but boundary prediction starts to vary as the radial immersion decreases (Gradišek, Kalveram, Insperger, Weinert, Stépán, Govekar, \& Grabec, 2005). The most familiar method of modal testing was the impact hammer test. The transfer function of existing Multi Degree of Freedom (MDOF) systems can be classified by the structural dynamic test. Firstly, the structure is excited with an impact hammer and the resulting vibrations are measured with displacement, velocity, or acceleration sensors (Altintas, 2000). Subsequently there has been research using piezoelectric sensors and actuators (Sims, Bayly, \& Young, 2005). This approach is used to predict milling SLD and gives greater control over the excitation signal than the impact hammer test. Yet it is more suitable for small-dimensioned tools because it is impossible to accurately strike the tool tip. In 2003, the Harmonizer method was proposed in which the sound of the cutting process was scanned using a microphone to 
detect the presence of chatter (Faassen, Van De Wouw, Oosterling, \& Nijmeijer, 2003). The chatter can be detected when the energy of the measured sound signal exceeds a certain threshold. In the research, a D-partitioning model was proposed to consider the spindle speed. Also, research has been carried out using an Active Magnetic Bearing (AMB) to identify the spindle tool system's FRF (Abele, Kreis, \& Schiffler, 2007). It allows a non-contact measurement to be obtained while the spindle is turned on.

Nowadays, the Finite Element Analysis Method (FEM) is widely used for stability simulation and prediction (Lan, Marty, \& Debognie, 2006; Mann, Young, Schmitz, \& Dilley, 2005; Movaheddy \& Mosaddegh, 2006). An alternative method involves the implementation of a combined algorithm linking off-line scheduling and on-line spindle speed ramping (Ismail \& Ziaei, 2002). In addition, there is research on other algorithms and methods that have been applied to various machining problems, however this paper focuses on the chatter suppression problem (Yusoff, Suffian, \& Taib, 2011). A method to detect chatter was proposed by online monitoring before the problem had time to fully develop. Early detection allows the operator to intervene in the process, thus avoiding chatter marks on the workpiece's surface (Faassen et al., 2003). However this method led to extra time being needed and reduced production. Researchers from NIST developed a design of an actuator using a permanent magnet to excite a rotating tool without requiring special skills. However, an uncontrollable force was generated which failed to predict the stable depth of cuts, thus another approach is needed. The paper presents the design of a prototype $\mathrm{C}$-shaped electro-mechanical actuator with a controllable force profile, that is easy to use offers more accurate prediction of the FRF behavior of the machine tool (Esterling, Caufield, Kiefer, Buckner, \& Jaju, 2003).

\section{MODAL TESTING}

Modal testing is used to identify the dynamic characteristics of the combination of the spindle, tool and tool holder of a machine (Ewins, 2000). Impact hammer testing was undertaken to determine the FRF of the tool in order to identify the expected dominant chatter frequency for the initial selection of spindle speed and feed rate ( Yusoff, Turner, Taylor \& Sims, 2010). Essentially a normal force was applied to excite the tool using an impact hammer, and the response is measured using an accelerometer or a displacement sensor, also a SigLab two-channel data acquisition system was connected to the hammer and accelerometer to determine the FRF (Altintas, 2000; Davies, Dutterer, Pratt, Schaut, \& Bryan, 1998; Faassen et al., 2003; Smith \& Tlusty, 1991; Tlusty \& Moriwaki, 1976; Yusoff et al., 2010). The diameter of the tooltip to length ratio is approximately 1.6 , which result in a relatively flexible tool compared to the stiffness of the tool holder and spindle. The measurement is repeated to obtain more accurate results. Then, the measured data are converted from time-domain to frequency domain using a Fast Fourier Transformation (FFT). This method is well suited for nonrotating tools, but cannot be used to identify the dynamics of a rotating spindle. Alternative suggestions are presented in an attempt to identify the spindle, tool and tool holder dynamics of a rotating spindle, but unfortunately these method cannot be used due to the fact that the excitation and the response cannot be simultaneously measured at the rotating tooltip (Faassen, 2007). Besides, skills are required to correctly perform impact hammer testing. The impact must be clean to produce the required broadband excitation. It must be of very short duration, and multiple hits or bounces must be avoided. Also, skill is necessary to ensure a consistent force input. Very few machinist 
or production engineers possess the experience or expertise to make impact hammer testing practical in a shop environment (Caufield, 2002). Besides the application to a machine tool, research has been carried out to determine the natural frequencies and modes of the rotating stationary disc, thus from the FRF obtained the desire modes can be easily established (Mehdigholi, 1991). In 1998, an impact hammer test was used to examine structural dynamic behavior, from the natural frequencies, damping ratio and mode shape of an aluminum plate (Bujang, Kamaruddin, \& Nordin, 2008).

FRF measurements are basically taken under stable conditions, where the test specimen is excited using an impact hammer or shaker driven by broadband signals (AlKhazali \& Askari, 2011). To obtain this measurement, a multi-channel FFT analyzer is used. In the conditions required for impact testing cannot be employed, FRF measurement will be made by attaching a shaker to the structure to create excitation (Comstock, 1999). Shaker excitation is most commonly used as an excitation technique for modal testing applications. To date there are many ways to set up shaker excitation ( Cloutier, Avitabile, Bono, \& Peres, 2009). Much research and testing has been conducted and used. A technique consider to avoid the effect of shaker - stinger interaction in modal test on a smaller structure (Anderson, 1990). Other research discussed the stinger material (Billhart, Hunt, \& Pierre, 1993). From previous studies, it is shown that modal testing applications are very sensitive to even small changes in the system, and thus the accelerometer mass and shaker-structure are usually assumed to have a negligible influence on the structure's dynamic behavior (Ashory, 1999). The type of excitation signals commonly used in modal testing are stepped or swept sinusoids, random, and impulsive (Ewins, 1984). Also there are limitations on the application of shaker testing on machine tools. The frequency response measured will not reflect the true system dynamics, and testing can take a long time to set up which means it is not suitable for use in a production environment. Shaker testing is also very costly. It generally needs more sophisticated and expensive equipment, such as signal generators, power amplifiers and the shaker. Besides that, shaker application need experienced expertise to be set up correctly (Caufield, 2002). Today they are many applications of electro-magnetic actuators, including fuel injection control in the production of molds and dies, and others in the automotive, aerospace and aeronautical industries. The paper introduces a table model method to compare the different types of EMA (Melgoza \& Rodger, 2002; Quintana, Ciurana, \& Teixidor, 2008).

From previous research and studies it has been shown that impact hammer and shaker excitation both had limitations in modal testing for use in a production environment. Thus another method had been studied to overcome this limitation. The electromagnetic actuator is non-contact method of excitation, yet it is more simple and easy to set up. The two common methods are compared with the electromagnetic actuator and listed in Table 1.

Table 1. Comparison of approaches to modal testing.

\begin{tabular}{lcccc}
\hline Type of excitation & Attachment & $\begin{array}{c}\text { Controllable } \\
\text { Force }\end{array}$ & $\begin{array}{c}\text { Setup } \\
\text { Setting }\end{array}$ & Cost \\
\hline Impact Hammer & Contact & No & Hard & Cheap \\
Shaker & Contact & No & Hard & Expensive \\
Electromagnetic & Non- & Yes & Easy & Cheap \\
Actuator & contact & & & \\
\hline
\end{tabular}


Previous research commonly uses a system of a permanent magnet on an electromagnetic actuator. A non-conventional electromagnetic actuator had been proposed, with which the dynamic model is derived before figuring out the unknown parameters using an adaptive controller to precise the position in the system. The magnet is attached to a motion pad and its movement is due to the repelling force of two coils (Chen, Lin, Huang, \& Fu, 2003). In 2008, an analytical solution by SchwarzChristoffel (SC) mapping was presented to determine the force acting on a moving coil in an EMA, and the result was validated using finite element methods (Markovic, Jufer \& Perriard, 2008; Sylvester, 1968). Later, a prototype of ahigh bandwidth electromagnetic fast tool servo (FTS) was designed and implemented for use in the diamond-turning of non-rotationally symmetric surfaces (Wu, Zhou, \& Xie, 2010). The results showed the effectiveness of both design and control approaches. This was followed by theoretical analysis and an experimental investigation into an EMA for a miniature magnetically-levitated rotating machine (Sheng-Ming, 2011). Even though the resulting force is too small, it effectively reduced rotor resonance-related oscillations. Because of its simple and effective performance, EMA has also been applied to engine components. An electromagnetic valve actuator has been designed, manufactured and demonstrated to observe its capabilities in controlling the force (Cope, Wright, Corcoran, Pasch \& Fischer, 2008). In general, the four main components in an electromagnetic system are the actuator, sensor, controller and power amplifier. The design of an electromagnet is dependent on the dimensions, required gap flux, and the current density of the winding (Sarkar, Biswas, Sarkar, Bhaduri, \& Banerjee, 2011). There are various geometries, which are magnet in $C, U$, and $E$ profile with different winding arrangements (Appun \& Ritter, 1975; Caufield, 2002; Yamamura \& Yamaguchi, 1990). A review on the scope and content of research in the field is ongoing.

\section{CONCLUSIONS}

In the literature it is observed that chatter can be controlled or avoided by predicting the combination of spindle speed, tool holder, and machine tool. There are various methods that can be applied for the minimization of chatter; however EMA is the most appropriate approach because it excites with a controllable force, is easy to set up and is cheaper than the other methods.

\section{REFERENCES}

Abele, E., Kreis, M., \& Schiffler, A. (2007). Online diagnosis and identification of high accuracy HSC machining centers. 6th International Conference on High Speed Machining, pp. 1-8.

Al-Khazali, H. A. H., \& Askari, M. R. (2011). Experimental technique to investigate vibration monitoring in revolving structures using oscilloscopic/modal testing. International Journal of Engineering Science and Technology, 3, 7799-7814.

Altintas, Y. 2000. Manufacturing automation: metal cutting mechanics, machine tool vibrations and CNC design. UK, Cambridge University Press.

Altintaş, Y., \& Budak, E. (1995). Analytical prediction of stability lobes in milling. CIRP Annals - Manufacturing Technology, 44, 357-362.

Anderson, I. A. (1990). Avoiding stinger rod resonance effects on small structures. Proceedings of the 8th International Modal Analysis Conference, pp. 673-678. 
Appun, P., \& Ritter, G. (1975). Calculation and optimization of the magnets for an electromagnetic levitation system. IEEE Transactions on Magnetics, 11 (1), 3944.

Arnold, R. N. (1946). The mechanism of tool vibration in the cutting steel. Proceedings of the Institution of Mechanical Engineers, 154 (4), 261-284.

Ashory, M. R. (1999). High quality modal testing methods. PhD Thesis, Imperial College of Science, Technology and Medicine, University of London.

Billhart, R. D., Hunt, D. L., \& Pierre, M. S. (1993). Advantages of excitation using plastic stinger rods. Proceedings of the 11th International Modal Analysis Conference, pp. 1217-1220.

Bujang, I. Z., Kamaruddin, K. A., \& Nordin, M. T. M. (2008). Identification of structural defects using modal technology. International Conference on Construction and Building Technology, pp. 193-200.

Caulfield, F. D. (2002). Electromechanical actuator development for integrated chatter prediction on high speed machining centers. Master Thesis, North Carolina State University, USA.

Chen, M. Y., Lin, T. B., Huang, S. G., \& Fu, L. C. (2003). Design, analysis and control of an electro-magnetic actuator. Proceedings of the American Control Conference (ACC), Denver, Colorado, pp. 3095-3100.

Cloutier, D., Avitabile, D. P., Bono, R., \& Peres, M. (2009). Shaker/stinger effects on measured frequency response function. Proceedings of the IMAC-XXVII, Florida, USA, pp. 1-7.

Comstock, T. R. (1999). Improving exciter performance in modal testing. Proceedings of the 17th International Modal Analysis Conference, Florida, USA, pp. 17701775.

Cope, D., Wright, A., Corcoran, C. J., Pasch, K., \& Fischer, D. (2008). Fully flexible electromagnetic valve actuator: design, modeling, and measurements. SAE Paper No. 2008-01-1350.

Davies, M. A., Dutterer, B., Pratt, J. R., Schaut, A. J., \& Bryan, J. B. (1998). On the dynamics of high-speed milling with long, slender endmills. CIRP Annals Manufacturing Technology, 47, 55-60.

Esterling, D., Caufield, F. D., Kiefer, A., Buckner, G., \& Jaju, P. (2003). Non-contact device for measuring frequency response functions of CNC machine tools. ASME International Mechanical Engineering Congress, pp. 77-83.

Ewins, D. J. (1984). Modal testing: theory and practice. Hertfordshire, Research Studies Press.

Ewins, D. J. (2000). Modal testing: theory, practice and application. UK, Baldock.

Faassen, R. P. H. (2007). Chatter prediction and control for high-speed milling. PhD Thesis, Eindhoven University of Technology, Netherlands.

Faassen, R. P. H., Van De Wouw, N., Oosterling, J. A. J., \& Nijmeijer, H. (2003). Prediction of regenerative chatter by modelling and analysis of high-speed milling. International Journal of Machine Tools and Manufacture, 43, 14371446.

Gradišek, J., Kalveram, M., Insperger, T., Weinert, K., Stépán, G., Govekar, E., \& Grabec, I. (2005). On stability prediction for milling. International Journal of Machine Tools and Manufacture, 45, 769-781.

Insperger, T., \& Stepan, G. (2002). Semi-discretization method for delayed systems. International Journal for Numerical Methods in Engineering, 55, 503-518. 
Ismail, F., \& Ziaei, R. (2002). Chatter suppression in five-axis machining of flexible parts. International Journal of Machine Tools and Manufacture, 42, 115-122.

Kiefer, A. J. (2004). Integrating electromechanical actuator hardware with receptance coupling substructure analysis for chatter prediction on high speed machining centers. Master Thesis, North Carolina State University, USA.

Koenigsberger, F., \& Tlusty, J. (1967). Machine tool structures. Vol. I: Stability against chatter. London, Pergamon Press.

Lan, J. V. L., Marty, A., \& Debognie, J. F. (2006). A stability diagram computation method for milling adapted to automotive industry. CIRP Second International Conference on High Performance Cutting, Vancouver, British Columbia, Canada.

Mann, B. P., Young, K. A., Schmitz, T. L., \& Dilley, D. N. (2005). Simultaneous stability and surface location error predictions in milling. Journal of Manufacturing Science and Engineering, 127, 446-453.

Markovic, M., Jufer, M., \& Perriard, Y. (2008). Analytical Force determination in an electromagnetic actuator. IEEE Transactions on Magnetics, 44, 2181-2185.

Mehdigholi, H. (1991). Force vibration of rotating discs and interaction with nonrotating structures. PhD Thesis, Imperial College of Science, Technology and Medicine, University of London, UK.

Melgoza, E., \& Rodger, D. (2002). Comparison of table models of electromagnetic actuator. IEEE Transactions on Magnetics, 38, 953-957.

Merrit, H. 1965. Theory of self-excited machine tool chatter. Journal of Engineering for Industry, 87, 447-454.

Movaheddy, M., \& Mosaddegh, P. (2006). Prediction of chatter in high speed milling including gyroscopic effects. International Journal of Machine Tools and Manufacture, 46, 996-1001.

Quintana, G., Ciurana, J., \& Teixidor, D. (2008). A new experimental methodology for identification of stability lobes diagram in milling operations. International Journal of Machine Tools and Manufacture, 48, 1637-1645.

Rantatalo, M., Aidanpaa, J. O., Goransson, B., \& Norman, P. (2007). Milling machine spindle analysis using FEM and non-contact spindle excitation and response measurement. International Journal of Machine Tools and Manufacture, 47, 1034-1045.

Sarkar, M., Biswas, P., Sarkar, P., Bhaduri, R., \& Banerjee, S. (2011). A review note on different components of simple electromagnetic levitation systems. IETE Technical Review, 28 (3), 256-264.

Schmitz, T. L., Ziegert, J. C., \& Stanislaus, C. (2004). A method for predicting chatter stability for systems with speed-dependent spindle dynamics. Aerospace Engineering, 32, 17-24.

Sheng-Ming, Y. (2011). Electromagnetic actuator implementation and control for resonance vibration reduction in miniature magnetically levitated rotating machines. IEEE Transactions on Industrial Electronics, 58, 611-617.

Sims, N. D., Bayly, P. V., \& Young, K. A. (2005). Piezoelectric sensors and actuators for milling tool stability lobes. Journal of Sound and Vibration, 281, 743-762.

Smith, S., \& Tlusty, J. (1991). An overview of modelling and simulation of the milling process. Journal of Engineering for Industry, 113, 169-175.

Sylvester, P. (1968). Modern electromagnetic fields. London, Prentice Hall. 
Tatar, K., Rantatalo, M., \& Gren, P. (2007). Laser vibrometry measurements of an optically smooth rotating spindle. Mechanical Systems and Signal Processing, 21, 1739-1745.

Tlusty, J., \& Moriwaki, T. (1976). Experimental and computational identification of dynamic structural models. Annals of the CIRP, 25, 497-503.

Tlusty, J., \& Polocek, M. (1963) The stability of the machine-tool against self-excited vibration in machining. Proceedings of the International Research in Production Engineering Conference, Pittsburgh, pp. 465-474.

Tobias, S. A. (1965). Machine tool vibration. New York: John Wiley.

Tobias, S. A., \& Fishwick, W. (1958). Theory of regenerative machine tool chatter. London, The Engineer.

Wu, D., Zhou, S., \& Xie, X. (2010). Design and control of an electromagnetic fast tool servo with high bandwidth. IET Electric Power Applications, 5(2), 217-223.

Yamamura, S., \& Yamaguchi, H. (1990). Electromagnetic levitation system by means of salient-pole type magnets coupled with laminated slotless rails. IEEE Transactions on Vehicular Technology, 39, 83-87.

Yusoff, A., Turner, S., Taylor, C., \& Sims, N. (2010). The role of tool geometry in process damped milling. International Journal of Advanced Manufacturing Technology, 50, 883-895.

Yusoff, A. R., \& Sims, N. D. (2008). Non contacting electromagnetic actuators for chatter stability analysis of milling tools. 9th International Conference on Vibrations in Rotating Machinery, pp. 305-316.

Yusoff, A. R., \& Sims, N. D. (2011). Determination of optimal variable helix and variable pitch tool geometry for chatter suppression in milling process. Journal of Advanced Manufacturing Technology, 5, 45-60.

Yusoff, A. R., Suffian, M. R. Z. M., \& Taib, M. Y. (2011). Literature review of optimization technique for chatter suppression in machining. Journal of Mechanical Engineering and Science, 1, 47-61. 